\title{
EL MOTIVO DE PUTIFAR EN LA TRAGEDIA GRIEGA*
}

JOSÉ MARfa LUCAS

UNED

Es cosa ya bien establecida la amplia incidencia del «Motivo de Putifar» en el material mítico greco-latino', que lo utiliza al menos en seis ocasiones, como veremos después. Pero mi pretensión en estas páginas va a ser la de destacar el frecuente uso que por su parte hicieron los poetas trágicos de este área del mito, poniendo así de manifiesto su gusto por esta temática, hasta el punto de llegar en alguna ocasión a alterar la línea general del relato tradicional previo con la intención de adaptarlo a los componentes básicos de esta otra unidad temática. Y, claro está, a la cabeza está una vez más Eurípides.

1. El primer cometido será lógicamente precisar antropológicamente qué entendemos por «motivo de Putifar». La simple denominación ya nos orienta rápidamente: en el cap. 30 del Génesis se nos cuenta el episodio de José, uno de los hijos de Jacob, durante su estancia en Egipto en casa de Putifar: éste, eunuco del Faraón, había comprado a José a unos ismaelitas a los que a su vez se lo habían vendido a sus propios hermanos, irritados por la aparente

* Este trabajo es una versión ampliada del texto de mi Comunicación al VIII Congreso Nacional de la Sociedad Española de Estudios Clásicos, celebrado en septiembre de 1991. Se encuadra en un Proyecto de Investigación financiado por la CICYT.

1 Cfr., por ejemplo, A. RuIz ElviRA, «Las grandes sagas heroicas y los cuentos populares», Jano 39, 1972, pág. 50. 
predilección que sentía Jacob por él. En casa de Putifar nuestro protagonista logró atraerse la plena confianza de su amo, que puso en sus manos la administración de todos sus bienes. En un momento dado la mujer de Putifar se enamora de José e intenta atraerlo a su lecho, pero en nuestro joven héroe prima la fidelidad a su dueño protector y rechaza la unión amorosa, ante lo que ella, indignada por el rechazo, le acusa en falso ante Putifar y consigue que éste la crea y encierre a José en la cárcel. Sin embargo, con el tiempo, y con la ayuda de Yahveh, José logrará triunfar en la corte del faraón y éste le otorgará como esposa a Asenat.

Tipológicamente podríamos decir que se trata de un relato amoroso en el que un personaje joven, que está en relación estrecha -amigo, hermano, hijocon otro mayor que él, infunde en la mujer del segundo una pasión amorosa incontenible que la lleva a declararle sus sentimientos, pero él la rechaza por fidelidad al marido y, en tal situación, ella, despechada, lo acusa ante su esposo de intento fallido de seducción, o incluso de violación, consiguiendo su propósito en un primer momento, lo que acarreará el enfrentamiento entre los dos hombres, pero al final quedará de manifiesto la verdad, lo que supondrá la denigración para la mujer y la exaltación del honesto joven. Ahora bien, una cosa debe quedar bien clara: no se trata de un caso más del multiforme triángulo amoroso del que las diferentes artes del relato han hecho un uso intenso hasta nuestros días, sino que ha adquirido en el terreno del folktale su categoría de motivo tradicional por poseer esas peculiaridades aludidas.

2. El motivo de Putifar lo encontramos ya desde fecha temprana, anterior a la redacción ya vista del episodio de José en el Génesis, y en áreas culturales diversas. Así, por ejemplo, es bien conocido el cuento egipcio de la Historia de los dos hermanos, que aparece recogido en un papiro tradicionalmente datado en torno al 1225 a.C. ${ }^{2}$ : el relato ${ }^{3}$ nos habla de dos hermanos, Anubis y Bata, que viven juntos y el pequeño tiene a su cargo los trabajos de la hacienda; de otro lado, Anubis está casado y, en una ocasión, aprovechando la ausencia del

2 Es el papiro D'Orbiney, descubierto y publicado por Rougé en 1852 (Revue Archéologique 8, 1852, págs. 385 y ss.).

${ }^{3}$ Una edición del texto en escritura jeroglífica puede consultarse en A. H. GaRdiner, LateEgyptian stories (Bibliotheca Aegyptiaca, I), Bruselas, 1932, págs. 9-29. Traducción en alemán: A. ERman, Die Literatur der Aegypter. Gedichte, Erzăhlungen und Lehrbuicher aus dem 3. und 2. Jahrtausend v. Ch., Leipzig, 1923, págs. 197-209; o más recientemente como apéndice a S. SCHOtT, Altägyptische Liebeslieder, Zürich, 1950, págs. 193 y ss. Traducción en francés: G. LefEBVRE, Romans et contes égyptiens de l'époque pharaonique, Paris, 1949, págs. 137 y ss. En inglés, aunque sólo la primera parte: J. B., PrITChard (ed.), Ancient Near Eastern texts relating to The Old Testament, Princeton, 1950, págs. 23-5, a cargo de J. A., WILSON; o de fecha más cercana en W. S. Simp- 
hermano mayor la mujer intenta atraerse al menor al lecho, pero éste rehúsa, y a continuación vendrá la peripecia consiguiente: la mujer acusa falsamente a Bata y pretende que su esposo mate a su hermano antes de que éste pueda ni siquiera defenderse, pues ella teme que se descubra la verdad; Anubis espera, así, a su hermano escondido detrás de la puerta del corral, pero cuando éste regresa al atardecer con los ganados, una vaca le advierte ${ }^{4}$ del peligro y huye; en la persecución el dios del sol interviene y, de manera prodigiosa, abre una zanja entre perseguidor y perseguido con un río lleno de cocodrilos; Bata, así protegido, se mutila ante su hermano en prueba de su honestidad, y esto hará que Anubis le crea, tras lo que regresará a su casa y, allí, dará muerte a su mujer y la arrojará a los perros 5 .

También en la Literatura india encontramos ejemplos del motivo de Putifar. En un amplio trabajo de hace ya bastantes años Maurice Bloomfield 6 hace un recorrido minucioso del material existente y, entre otros ejemplos más o menos próximos, nos describe dos casos que se adaptan plenamente al prototipo. Primero describe el episodio del príncipe Paduma, donde el triángulo es esta vez: rey-príncipe-madrastra, y en cuyo desenlace intervienen una divinidad y el rey de los dragones en ayuda del maltratado joven honesto, lo que supone el componente mágico-maravilloso frecuente en este tipo de relato. A continuación Bloomfield nos cuenta la historia del príncipe Kunala, hijo del emperador Asoka, que es víctima igualmente de la pasión incontenible de su madrastra, a resultas de la cual será castigado con la ceguera, pero al final su inmensa bondad hará que milagrosamente recupere la vista y la pérfida esposa es quemada viva.

En ocasiones se pretende ver el motivo de Putifar en relatos en los que, a mi juicio; falta alguno de los elementos consustanciales: enamoramiento contra la norma de un triángulo muy concreto/intento fallido de seducción / calumnia por despecho y/o por defenderse ante posteriores delaciones ante el marido. Un ejemplo podría ser un relato cananeo que conocemos a través de un texto hetita: el dios Elkunirsa está casado con la diosa Asertu, que se enamora del dios Baal,

SON (ed.), The Literature of Ancient Egypt, New Haven, 1972, pags. 92-107. En español puede consultarse una versión hecha para una colección juvenil, aunque no obstante muy próxima al original, en Dioses y Faraones de la Mitología egipcia, Madrid, 1986, págs. 77-83, que es una traducción de una obra semejante inglesa (Gods and Pharaohs from Egyptian Mythology, 1982, con texto de G. HARRIS).

4 Esta posibilidad de algunos personajes de hablar con los animales también aparece en el material mítico griego.

5 El relato tiene una segunda parte que no tiene ya nada que ver con el motivo de Putifar, pero en la que aparecen diversos temas bien conocidos en el material mitografico griego.

6 M. BLOOMfield, wJoseph and Potiphar in Hindu fiction», TAPhA 54, 1923, 141-67. 
pero éste, inmediatamente después del intento de seducción, acude presto a decírselo al esposo, que le incita a unirse a su mujer para humillarla; además, en este punto está rota la tablilla, lo que nos impide seguir de cerca la marcha del relato, pero más adelante vuelve a recuperarse el texto y, entonces, vemos al matrimonio unidos frente a Baal, que se libra de la muerte tramada por aquéllos porque se lo advierte por adelantado Istar, metamorfoseada en un pajaro ${ }^{7}$. Lo mismo podrá decirse de ciertos episodios indios recogidos por el ya mencionado Bloomfield. Tal vez, sobre todo en el caso del relato cananeo dada su antigiiedad, podría decirse a lo más que se trata de estadios previos a su forma canónica. Pero en éste como en los demás campos es preciso establecer unos rasgos necesarios para que pueda hablarse de tal o cual fenómeno, porque lo contrario nos llevará indefectiblemente a la mezcla indiscriminada de los datos. Ahora bien, esto no va en contra de que luego tales elementos esenciales puedan estar ampliados con múltiples variantes derivadas de las diversas tradiciones que actúan en este campo.

3. Pero antes de entrar a tratar el material propiamente griego, conviene que nos detengamos un momento a perfilar con una mayor precisión la estructura formal del motivo de Putifar desde una perspectiva ya puramente literaria (utilizo aquí el término literario lógicamente en un sentido lato, como material modelable en cualquier tipo de relato). Así, pues, podríamos decir que el esquema general consta de cinco momentos. El primero corresponde al de enamoramiento: en el contexto de un matrimonio hay un tercer elemento, masculino, que reúne las características de juventud y de relación estrecha, familiar o no, con el marido; pues bien, de este tercer personaje se enamora la esposa de forma incontenible. Luego viene el intento de seducción protagonizado por ella y el consiguiente rechazo por parte de él, que prefiere seguir los dictados de lealtad al esposo. En un tercer momento tiene lugar la falsa acusación: la esposa, o bien por despecho, o bien ante el temor de ser delatada ante su marido, o bien por ambas cosas, se lamenta calumniosamente ante éste de la falsa deslealtad del tercer miembro del triángulo, y muy frecuentemente apoya su declaración con variados tipos de argucias - normalmente un estado físico deplorable- . Tras esto vienen los intentos de defenderse por parte del calumniado. Finalmente estaría el descubrimiento de la verdad, con el castigo consiguiente para la mujer pérfida y la salvación y exhaltación para el joven honesto.

7 Una traducción de este texto hetita puede verse en ANONIMO, Textos literarios hetitas, ed. preparada por A. BERNABE, Madrid, 1979, págs. 123-9. 
4. A la luz de este esquema formal y dado lo atractivo de su temática, en especial a partir de un momento dado en la evolución de la Tragedia griega en el propio siglo $\mathrm{V}$ a.C., es fácilmente comprensible que una tal línea argumental gozase de un encanto especial entre los poetas trágicos a la hora de buscar la temática de sus piezas. Y para ello, por supuesto, contaban con el fondo mítico, en el que este tema aparecía en repetidas ocasiones, como veremos. El primer testimonio, y más importante, de la incidencia del motivo de Putifar en el Teatro grecolatino es la constatación de que los seis mitos existentes al respecto sirvieron al menos en alguna ocasión como núcleo argumental de alguna obra dramática, frente a otras muchas áreas que nunca tuvieron la fortuna de subir a escena. Y a esto habría que añadir un segundo dato, que es el intenso uso, además, de que los poetas hicieron de alguno de esos temas, nueva prueba del atractivo que debió de ejercer el motivo de Putifar, subyacente a las historias particulares, en los dramaturgos y público atenienses.

De manera más precisa y empezando por el aspecto formal, es claro que esa estructuración descrita del relato-tipo se avenía maravillosamente bien a las líneas generales de composición de la Tragedia griega, puesto que los tres primeros momentos, de contenido esencialmente narrativo, encajaban perfectamente en el período inicial de toda tragedia, lo que no va en contra de que en cada caso concreto el poeta pudiese dar entrada a alteraciones de diversa consideración según el punto que quisiera destacar o, por el contrario, hacer pasar desapercibido. Luego, el núcleo dramático, o sea, el período agonal, sería el lugar oportuno para dar cabida al intento de defenderse por parte del calumniado. Y la acción se cerraría con un nuevo momento narrativo donde quedaría de manifiesto la auténtica verdad del episodio amoroso. Con sólo revisar la marcha de la acción dramática del Hipólito euripídeo conservado se comprueba la oportunidad de estas consideraciones.

Pero también temáticamente debía de haber una gran sintonía entre este motivo de Putifar y los temas trágicos, y la mejor prueba de ello es que en un caso, el de Fénix como veremos más abajo ${ }^{8}$, la Tragedia llegará incluso a alterar profundamente el relato tal y como se conocía ya por el mismísimo Homero en un amplio pasaje de la Ilíada, y dadas estas dos circunstancias es claro que la voluntad euripídea por introducir la alteración fue intensa, así como sería difícil que pasase desapercibida al público.

4.1. Empecemos por el triángulo Preto / Estenabea / Belerofontes. Ya en la Iliada $^{9}$ encontramos una amplia exposición del episodio de Belerofontes,

${ }^{8}$ Cf. apartado 4.4.

9 VI 155 y ss. 
cuando Diomedes y Glauco se encuentran en el campo de batalla y cada uno pasa a exponer su ascendencia, en ese famosísimo pasaje en que el linaje humano es comparado en su futilidad al de las hojas. Así, Glauco, nieto de Belerofontes, cuenta cómo éste, vasallo de Preto en la región argiva, destacaba en belleza y valentía, pero se vio desterrado de allí debido a un percance amoroso: Antea ${ }^{10}$, mujer de Preto, se enamoró de manera incontenible de Belerofontes y pretendio unirse a él en secreto amor, pero el honesto joven la rechaza y ella entonces lo acusa falsamente ante su marido que, eludiendo darle él mismo muerte por escrúpulos, lo manda a Licia llevando para el soberano del país asiático una carta en la que se indica que se dé muerte al portador ${ }^{1}$. Allí el rey lidio lo sometió a diferentes pruebas a primera vista insuperables, de las que nuestro héroe sin embargo salió victorioso, al final de las cuales, y dado que era evidente que se trataba del hijo de algún dios, obtuvo la mano de la hija del rey, de la que tuvo tres hijos ${ }^{12}$.

Éstas son en esencia las líneas generales del relato en Homero, y curiosamente coinciden en una gran medida con las dos grandes enciclopedias mitográficas de época tardía: Apolodoro ${ }^{13}$ e Higino ${ }^{14}$. Pero en este caso tenemos la fortuna de disponer de un argumento de la tragedia euripídea titulada Estenebea ${ }^{15}$, en el que podemos constatar las innovaciones que introdujo la Tragedia $\multimap$ al menos la adaptación euripídea-, algunas de las cuales veremos que van a caracterizar algunos de los ejemplos del motivo de Putifar en el mito griego.

A juzgar por el testimonio mencionado, en Eurípides la acción era de esta manera: Belerofontes, hijo del rey de Corinto, comete un homicidio invo-

10 Tradicionalmente se piensa que el nombre de Estenebea fue una invención de los trágicos, basándose en el testimonio de APOLODORO, Biblioteca II 2.1. Últimamente, a partir de la publicación del P. Oxy 2487 (Hesiodo, Fr. $129 \mathrm{M}$-W), sabemos que ya Hesíodo conocía este otro nombre de la mujer de Preto.

11 Obsérvese que en este punto del relato se está utilizando otro viejo recurso del folklore tradicional: el motivo de Urías, que recibe este nombre del episodio de David y el hitita Urías en $2 \mathrm{Sa}$ muel 11, donde se narra el adulterio de David y Betsabee, esposa de Urías, al que el rey hace portador de una carta en la que se ordena su propia muerte.

12 La narración pasa a continuación a contar el final infortunado de nuestro héroe, cuando odiado de los dioses - no se nos dice la causa - vivía en soledad privado de dos de sus hijos, muertos a manos de Ares y Ártemis. Pero esta segunda parte no nos interesa en estos momentos.

13 APOLODORO, Biblioteca II 3.1.

14 Higino, Fábulas 57.

is Ya en el siglo XIX se conocía este argumento recogido por un escoliasta en un manuscrito de Gregorio de Corinto y, en consecuencia, está editado por Nauck. Pero a principios del XX, en el manuscrito del Comentario a Hermógenes de Juan Logóteta, apareció una nueva versión con algunas variantes pero, sobre todo, con un amplio parlamento de más de treinta versos perteneciente al Prólogo de la tragedia y que estaba en boca del propio Belerofonte. 
luntario $^{16}$ y acude al lado de Preto, rey de Tirinto, en ayuda de purificación. Pero en un momento dado tiene lugar el enamoramiento y la peripecia descrita, con el envío a la corte de Yóbates en Asia, suegro de Preto. Allí es sometido sólo a la prueba de matar a la Quimera, para lo que se sirve de Pegaso. Y tras la victoria retorna a Tirinto donde censura a Preto su comportamiento y amenaza a Estenebea con estrangularla ${ }^{17}$. No obstante, Belerofonte se entera de que el matrimonio por segunda vez está tramando contra él y, entonces, convence a la mujer para llevarla con él lejos a lomos de Pegaso, proposición a la que ella accede y, cuando van por los aires, la hace caer del caballo al mar a la altura de la isla de Melos. Su cadáver lo traerán a Tirinto unos pescadores milesios, y también llegará Belerofontes reconociendo que todo ha sido obra suya, puesto que de esta manera se ha vengado del doble engaño de que fue objeto por parte de la pareja: de ella haciéndola pagar con la vida, de él con el dolor.

Vemos, pues, la complejidad que introdujo Eurípides al hacer volver a nuestro héroe a Tirinto, muy probablemente, a mi juicio, con la intención de dar la posibilidad de que quedara más de manifiesto la verdad entre los propios protagonistas. Pero, a parte de este componente, es preciso fijar la atención en otros elementos que vamos a volver a encontrar en otros triángulos. En primer lugar, vemos que no se trata de una relación padre-hijo, y que en este caso el

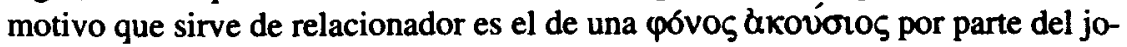
ven, que viene de fuera en solicitud de purificación. También en estos casos de «homicidio voluntario» no hay enfrentamiento directo entre los componentes masculinos, al menos en un primer momento, sino que son sometidos a una serie de pruebas extraordinarias con la intención de que sean esas circunstancias las que acaben con la vida del en ese momento aún desleal huésped.

Veamos ahora la incidencia que tuvo este relato mítico en la Tragedia. En primer lugar, ya he hecho alusión a la Estenebea de Eurípides. No voy a entrar aquí en un intento pormenorizado de reconstrucción porque me llevaría mucho más lejos de lo que pretendo en estas páginas, pero es claro, a partir de la información proporcionado por el argumento aludido, que había una parte inicial narrativa en torno al conflicto creado con el enamoramiento de Estenebea, y que esto ya se iniciaba en el parlamento con que el joven héroe abría la tragedia. Luego había un período de enfrentamiento con Preto y, tal vez, incluso con la esposa. Finalmente, la acción se cerraba con el descubrimiento de la muerte de

16 No voy a entrar aquí en el particularismo de los nombres y otros pormenores, que pueden consultarse en cualquier Manual de Mitología.

17 El argumento, conocido a principios de siglo, altera aquí diciendo que la amenaza con enviarla a Asia. 
Estenebea y la llegada de Belerofontes a escena explicándolo y justificándolo todo. La crítica filológica tiene planteado un problema de difícil solución a este respecto: la postura tradicional ${ }^{18}$ ha sido la de suponer que la parte inicial de la pieza es previa a la marcha del héroe a suelo asiático, pero es cierto que ello supondría dos cortes cronológicos en marcha de la acción: el primero, entre la marcha al lado de Yóbates y su vuelta a Tirinto; el segundo, entre la partida de la confiada Estenebea y la llegada de la noticia de su triste final con la entrada igualmente de Belerofontes. Desde hace unos años ${ }^{19}$ se ha sugerido que la acción dramática comenzaba realmente a la vuelta del héroe y que, por lo tanto, en el texto conservado del Prólogo falta la parte en la que hacía alusión a lo ocurrido en Lidia: es evidente que así los problemas antes mencionados se solucionarían y que la marcha de los acontecimientos en la escena sería más compacta; pero no es menos cierto que, si aceptamos que la obra comenzaba con el regreso de Belerofontes a Tirinto tras su estancia al lado de Yóbates, en ese caso a mi juicio el sentido general de esta innovación del retorno del héroe, así como la impresión que uno saca del argumento, no se avienen con la decisión que nuestro personaje manifiesta en el fragmento recuperado del Prólogo, donde expone su pretensión del retirarse al campo abandonando el palacio, porque no quiere que su presencia siga creando problemas y que, al final, termine por descubrirse la verdad y la vergüenza cubra a la esposa de su protector con el consiguiente derrumbamiento de la casa, postura ésta que sería más comprensible si aún no hubiera tenido lugar la partida, consecuencia de la falsa acusación ante Preto.

Pero de alguna manera esta variante del motivo de Putifar tuvo que estar presente en el Yóbates sofocleo, puesto que probablemente este otro poeta trasladó la acción a la corte lidia con la narración de lo que allí le acaecía a nuestro joven héroe. Sugiero aquí esta posibilidad no fundándome en los fragmentos $u$ otros testimonios conservados, sino por la circunstancia de que en las fuentes mitográficas no hay otro episodio ni importante ni conflictivo en la vida de Yóbates a excepción de su participación en el relato que aquí trato. Por lo tanto, podemos decir que el motivo de Putifar debía de estar presente al menos en el trasfondo de la problemática concreta de esta pieza sofoclea.

18 Es el criterio ya de U. von WILAMOWITZ, «De Euripidis Stheneboea», $C P h, 3,1908$. 22-32. Más recientemente, T. B. L. WEBSTER, The tragedies of Euripides, Londres, 1967, págs. 804. Y últimamente, E. M. PapamiChael, «Bellerophon and Stheneboea (or Anteia)», Dodone 12, 1983, 45-74.

19 P. Zuhlke, «Euripides' Stheneboia», Philologus 105, 1961, 1-15 y 198-225. O también, D. KorZeniewsKı, «Zum Prolog der Stheneboia des Euripides», Philologus 108, 1964, 45-65. 
Sabemos que Eurípides escribió una obra titulada Belerofontes, pero lo poco conservado nos permite afirmar con seguridad que la acción trataba del último período de la vida real del héroe, cuando por otras razones se había hecho odioso a los dioses, por lo que no tiene nada que ver con la temática que aquí perseguimos. Finalmente, sabemos por la $S u d a^{20}$ que el prolífico Astidamante II, en el siglo IV, escribió otro Belerofontes, del que no podemos decir nada sino sólo suponer que probablemente recreaba la homónima pieza euripídea.

4.2. El segundo triángulo del motivo de Putifar en el mito griego es el de Acasto / Astidamía / Peleo.

Peleo se casa con Antígona, hija de Euritión, rey de Ftía, pero en la cacería del jabalí de Calidón mata involuntariamente a su suegro ${ }^{21}$, por lo que se refugia en Yolcos, donde el rey Acasto lo purifica. Allí, la reina Astidamía se enamora del recién llegado y pretende unirse a él, pero se ve rechazada y, llena de rencor, da paso a la consabida calumnia ante su esposo. Acasto la cree, pero no se atreve a matar a Peleo directamente, sino que lo expone a una «prueba» diffcilmente superable: al final de una cacería en el monte Pelión es abandonado dormido y Acasto le oculta la espada con la que poder defenderse de las fieras salvajes $^{22}$, pero Quirón, el Centauro bueno, lo ayuda encontrándole el arma en el momento preciso. Al final, Peleo se vengará del matrimonio: en Apolodoro ${ }^{23}$ se nos dice que Peleo volvió a Yolcos y despedazó a Astidamía, pero en Hesíodo $^{24}$ encontramos en dos ocasiones la imprecisa expresión de «arrasó Yolcos», y un escoliasta a Apolonio de Rodas ${ }^{25}$ afirma que Peleo acabó también con la vida de Acasto.

También este episodio, perteneciente a la época de juventud del mito de Peleo, es conocido desde los primeros momentos en nuestras fuentes ${ }^{26}$. En cuatro fragmentos de Hesíodo, pertenecientes todos ellos al Catálogo de las

20 La Suda, $\alpha 4265$.

21 Nuevamente, como en el triánguló anterior, volvemos a encontramos con el motivo del «homicidio involuntario» cuando la relación entre los personajes masculinos no son padre-hijo. No obstante, en este caso vemos que se incumple la característica de «joven».

22 También aquí, como en el anterior triángulo, volvemos a encontramos con el recurso de someter al calumniado a una «prueba» de especial dificultad . Cf. A. RuIz de Elvira, «De París y Enone a Tristán e Iseo», $C F C 4,1972,134-6$, donde sugiere la existencia del carácter de auténtica ordalía en esta prueba de Peleo, basándose en el primero de los tres escolios a ARISTÓFANES, Nubes 1063, donde el escoliasta pone en boca de Adrasto las palabras clave: «Si es justo, se salvará».

23 APOLODORO, Biblioteca III 13.3 y 7.

24 Hesíodo, Fr 211 y $212 \mathrm{~b}$.

25 Sch. a APOLONiO DE RODAS, 1224.

26 No obstante, la versión más pormenorizada está en APOLODORO, Biblioteca III 13.3 y 7 . 
mujeres $^{27}$, se narran diversos momentos del relato: el del ocultamiento de la espada y la mención de posterior destrucción de Yolcos; más aún: en un escolio a la lliada ${ }^{28}$ se nos dice que Hesíodo «expuso por extenso lo concerniente a Peleo y a la mujer de Acasto». En Píndaro lo encontramos mencionado, al menos de pasada, un par de veces también, y ello en la primera mitad del siglo $\mathrm{V}^{29}$. Finalmente, Aristófanes, en Las nubes 1063 , hace una muy somera alusión: «... Peleo, por ejemplo, consiguió su cuchillo por este motivo» ${ }^{30}$. En definitiva, podemos deducir con seguridad que este episodio de Peleo y Astidamía era bien conocido en el siglo $\mathrm{V}$.

Tipológicamente observamos que vuelven a repetirse una serie de elementos visto en el triángulo anterior, en el que también se daba una relación extrafamiliar entre los componentes masculinos. Así, reaparece la circunstancia de un «homicidio involuntario" como punto de arranque; tampoco hay un enfrentamiento directo entre ellos, sino una estratagema subrepticia a resultas de la cual se espera alcanzar la deseada venganza. Los restantes elementos pertenecen al tipo general ya descrito.

Pues bien, sabemos que Sófocles escribió dos tragedias en torno a nuestro esforzado héroe: un Peleo y Las mujeres de Ptía, pero podemos afirmar con gran probabilidad que en ambas piezas, sobre todo en la primera, la acción no versaba sobre el episodio que aquí tratamos ${ }^{31}$. Ahora bien, éste no es el caso del Peleo euripídeo, donde la situación es más confusa: por el apoyo tanto de los fragmentos como de cualquier otro tipo de información no podemos realmente decir con seguridad qué parcela del mito de Peleo utilizaba Eurípides y, en consecuencia, la crítica filologica ha estado siempre escindida en dos grandes bloques: los partidarios del motivo de Putifar, propuesta que se remonta al mismísimo Welcker en los primeros decenios del s. XIX, y frente a ellos los que piensan en el episodio del final de la vida del héroe cuando, antes del regreso de su nieto Neoptólemo, es expulsado del reino por Acasto y sus hijos. No obstante, en nuestra época hay una inclinación preferente por la primera opcion ${ }^{32}$, dado el gusto de Eurípides por este tipo de argumento, como estamos viendo, así

27 Hesído, Fr. 108, 209, 211 y 212 b.

28 Sch. llíada VI 164 (=HESIODO, Fr. 208).

29 PÍNDARO, Nemea IV 56 y V 27 ss. En ambos casos, logicamente, se trata de odas dedicadas a vencedores procedentes de Egina, la patria originaria de Peleo.

30 Está hablando el Argumento Justo y propone el caso de Peleo como ejemplo de los favores que se obtienen cuando se es honesto.

31 Para más detalles al respecto, cf. J. M. LuCas, Sófocles. Fragmentos, Madrid, 1983, págs. 249-54 y 349-50.

32 Cf., por ejemplo, T. B. L. Weaster, Op. cit. en nota 18, pág. $85 \mathrm{~s}$. 
como por la posibilidad de entender algunos fragmentos dentro de este episodio. Y poco más se puede decir de esta tragedia dados los datos que por ahora poseemos sobre ella.

4.3. El tercer triángulo es el de Cicno / Filonoma / Tenes: Cicno era un rey de la región troyana y, de su primer matrimonio, tuvo un hijo, Tenes, y una hija, Hemítea. Tras la muerte de su esposa se casa en segundas nupcias con Filónoma, que se enamora perdidamente de su hijastro Tenes. Éste la rechaza, pero ella lo acusa calumniosamente ante su marido de intento de seducción, presentando como testigo a un flautista llamado Eumolpo ${ }^{33}$. Cicno - sin dar opción a su hijo a defenderse, según alguna fuente ${ }^{34}$ - encierra en una urna a los dos hermanos y los arroja al mar, pero las olas arrastrarán el cofre hasta las playas de una isla en frente de Troya, que a partir de ese momento se llamará Ténedos. Cicno, por su parte, termina enterándose de la verdad ${ }^{35} \mathrm{y}$, tras dar muerte a Filónoma, se encamina al lado de su hijo en busca de la reconciliación, punto éste en el que hay una excisión en las fuentes: Conón ${ }^{36}$, por ejemplo, nos cuenta que el hijo rechazaba la pretensión paterna; por el contrario, un escolio a Licofrón ${ }^{37}$ nos ofrece un final feliz en el que Cicno, tras acabar con su segunda esposa, vivía feliz en Ténedos con sus hijos.

Por la cronología de las fuentes ${ }^{38}$ puede deducirse con verosimilitud que la elaboración literaria de este mito es de fecha reciente, puesto que prácticamente en la mayoría de las ocasiones se trata de referencias en autores postclásicos ${ }^{39}$. Ahora bien, hay una excepción importante sobremanera para nosotros: sabemos que en el siglo $\mathrm{V}$ se compuso una tragedia titulada Tenes y que versaba sobre

33 Algunas fuentes lo llaman Molpo.

34 CONON, 28, que utiliza concretamente la expresión zuxpl $\tau \omega \zeta$.

35 En un resto papiráceo, sobre el que volveré más abajo, se dice expresamente: «... cambió de opinión ...cuando se enteró que Tenes estaba sano y salvo en la isla de enfrente». Esta circunstancia tal vez habría que ponerla en relación con esas «pruebas» que hemos visto en los casos anteriores, en los que no hay enfrentamiento directo, sino que se somete al calumniado a unos peligros aparentemente insalvables, y cuya superación es precisamente la confirmación de la inocencia del héroe. En este caso esto se avendría bien con la ausencia de enfrentamiento entre los dos hombres mencionada por alguna fuente, aunque ésta no es la norma cuando se trata de una relación padre-hijo, como veremos más tarde.

$36 \mathrm{Cf}$. nota 34.

37 Sch. LiCOFRON 232.

38 Para los datos precisos, de cuyo particularismo podemos aquí prescindir, cf. C. ROBERT, Die griechische Heldensage (vol. II/l de la Griechische Mythologie de L. PRELLER), Berlín, 1920, 4 ed., págs. 385-8.

39 Para el problema delicado del origen de este mito, cf. F. Jouan, Euripide et les legendes des Chants Cypriens, París, 1966, págs. 306-8. 
este episodio de la vida de este héroe de la región troyana. Veamos los datos: Estobeo $^{40}$ nos trasmite una cita de una tragedia titulada Tenes y que él atribuye a Eurípides. De otro lado, Tumer ha publicado hace unos años un rollo de papi${ }^{\mathrm{r}^{4}}$, de comienzos del siglo II d.C., conteniendo una serie de argumentos de piezas de Eurípides, entre los que se incluye uno relativo al aludido episodio de Tenes, con alusión incluso a un testigo ${ }^{42}$ :

... encerrando... ${ }^{43} \ldots$ testigo de los... ${ }^{44}$... cambió de opinión cuando oyó que Tenes estaba sano y salvo en la isla de enfrente: a instancia de Apolo llamó a la isla Ténedos y dio muerte a la mentirosa mujer.

Finalmente, la Vida y Genealogía de Eurípides 45 nos informa que hay tres tragedias espurias entre las tradionalmente atribuídas a Eurípides (Tenes, Radamantis y Pirítoo), testimonio este último que, dejando a un lado el problema de autor, nos vuelve a certificar la existencia de una tragedia titulada Tenes.

En conclusión, en el caso del mito de Tenes, en cuya parte primera vemos que aparece una vez más el motivo de Putifar, es incuestionable que en el siglo $\mathrm{V}$ a. C. se escribió una tragedia que versaba sobre este área del relato y, con lógica dado el carácter reciente de su aparición, es fácilmente aceptable que esta adaptación escénica tuvo que jugar un papel importante en la configuración y expansión definitivas de este mito.

Cuestión más problemática es la relativa a la autoría de esta pieza y, aunque no es éste el lugar de entrar a fondo en ese problema, haré una breve alusión a él en la medida en que el tema aquí tratado puede tal vez arrojar alguna luz al debate. Tradicionalmente se ha atribuido esta pieza a Eurípides, basándose principalmente en Estobeo, fuente del único fragmento conservado ${ }^{46}$

40 Estobeo III 2.15 (=Critias 21 Snell-Kannicht, aunque sobre los problemas de autorfa véase más abajo).

41 POxy 2455. 175, Londres, 1962.

42 Recordemos que en las descripciones posteriores de este relato mítico se habla de un flautista, Molpo o Eumolpo, que hace el papel de falso testigo del intento de seducción, como he seña-
lado más arriba.

43 Turner sugiere la siguiente reconstrucción: «encerrando en una urna», en clara alusión al he señalado antes.

44 SNell, en su edición de Critias (43 F.20 en el vol. I de los TrGF), sugiere en el texto una idea de este tipo: «poniendo a Molpo por testigo de lo sucedidow.

45 Líneas 35-6 de la ed. de L. Meridier, en el tomo I de la col. Budé, París, 19615 , p. 2. 
Ahora bien, ya desde la propia Antigüedad se puso en duda una tal atribución ${ }^{47}$ y en época moderna se ha generalizado la opinión de Wilamowitz, que la atribuye a Critias ${ }^{48}$. Ahora bien, desde los años sesenta se han publicado varios restos papiráceos ${ }^{49}$ conteniendo argumentos de obras euripídeas, y entre ellas se encuentra uno dedicado a resumir el contenido de un Tenes. Por supuesto que puede seguir pensándose que también estas nuevas fuentes cayeron en ese hipotético error detectado por la Vida de Eurípides y defendido por Wilamowitz; pero no es menos cierto que la nueva documentación pone en tela de juicio la oportunidad de ese rechazo de la autoría de Eurípides, autoría ésta que vendría también refrendada por la inclinación de Eurípides a poner en escena temas en los que se daba el motivo de Putifar, por el que nuestro trágico debió de sentir una predilección especial como tratamos de poner en evidencia en estas páginas.

4.4. El cuarto triángulo está formado por Amíntor / Ptía ${ }^{50}$ / Fénix.

Fénix es hijo de Amíntor, rey de Eleón en Beocia. Ya el propio Homero, en una amplia tirada de versos del canto IX de la Ilíada ${ }^{51}$, nos cuenta el episodio amoroso de Fénix con una concubina de su padre: su madre le había convencido para que la sedujera y, así, el anciano aborreciera a la joven. Nuestro héroe llevó efectivamente a cabo el encargo, pero su padre se enteró y lo maldijo, ante lo que Fénix optó por huir a Ptía. En la Épica se trata, pues, de un tipo de relato diferente del que aquí nos ocupamos: es el joven el que intenta y consigue seducir a la mujer, situación totalmente anómala en el esquema esencial del motivo de Putifar. Y, respecto al desenlace, se nos dice simplemente que Fénix huyó al lado de Peleo en Ptía, donde entrará en contacto con Aquiles, comenzando una nueva etapa de su existencia mítica.

Ahora bien, en este caso vamos a encontrarnos con un hecho enormemente importante para nuestros intereses en estas páginas: un escolio al pasaje homérico aludido ${ }^{52}$ nos dice que en los trágicos la historia era de otra manera, lo que coincide con la versión que nos transmite Apolodoro ${ }^{53}$, en la

${ }^{47}$ La anónima Vida de Eurípides (pág. 2,35 Méridier) la considera apócrifa, junto con un $R a$ damantis y un Pirftoo.

48 Cf., por ejemplo, SNELL en su edición de los fragmentos de los trágicos, vol. I, págs. 1823 , donde pueden consultarse los pormenores bibliográficos.

49 Para los pormenores bibliográficos, cf. la segunda edición de la obra mencionada en la nota anterior, a cargo de R. KANNICHT.

50 El Sch a llíada IV, 448, la llama Clitia.

51 HOMERo, llíada IX 447-484.

52 Cf. nota anterior.

53 APOLODORO, Biblioteca III, 13.8. 
que puede verse con plena seguridad un resumen del Fénix euripídeo, dado que también así encajan bien en ese trazado narrativo los fragmentos que conservamos de esa pieza: la concubina intenta seducir al joven príncipe, pero ante el rechazo de éste le acusa en falso ante Amíntor que, en un arrebato de cólera, deja ciego a su hijo, pero posteriormente el centauro bueno, Quirón, lo curará y Peleo lo hará, retornando así a Homero, soberano de los dólopes. De esta forma, pues, vemos cómo el relato anterior a la Tragedia se reorienta y convierte en una variante canónica del motivo de Putifar. De otro lado, la tradición posterior se apoyará primordialmente en la versión de la Tragedia $^{54}$.

Es clara, pues, la importante variación que introdujo la Tragedia: la iniciativa de la seducción arranca ahora de la mujer, punto éste esencial en el motivo de Putifar. En este sentido, y aunque ni Apolodoro ni las demás fuentes lo dicen expresamente, probablemente en esta nueva adaptación había muerto la madre de Fénix, de tal manera que Ptía es ahora la nueva esposa del padre y, por lo tanto, madrastra de nuestro héroe, en consonancia nuevamente con el prototipo del relato. Esta sugerencia se fundamenta perfectamente en varios de los fragmentos conservados ${ }^{55}$.

Este episodio de Fénix gozó de un éxito destacado en el Teatro grecolatino. Tanto Sófocles como Eurípides escribieron sendos Fénix, de los que al menos el del segundo podemos afirmar con seguridad que desarrollaba esta temática. En el caso de Sófocles la situción es mucho más incierta, y el empleo que en ocasiones se ha hecho del Fr.720, donde se califica de «ramoneadora» a la mujer que tiene trato íntimo con muchos hombres como medio de subsistencia, a mi juicio no es un apoyo decisivo, sino solamente sugerente. Igual sucede con el poeta trágico Ión de Quíos, dentro del mismo siglo $\mathrm{V}$ a.C., del que sabemos que compuso dos Fénix, uno de los cuales, subtitulado en las fuentes Ceneo (o Eneo, según otras), no versaba evidentemente sobre esta parte de la saga mítica de nuestro héroe; y del segundo, desgraciadamente, la información es tan escasa que es arriesgado hacer una conjetura medianamente firme, y sólo el interés despertado por el tema de la concubina, al que me referiré más abajo, puede inducimos a sugerir que aquí tendríamos una nueva versión. Pero que este tema tuvo gran acogida entre el público asistente al teatro lo vuelve a demostrar el hecho de que en el siglo IV Astidamante Il escribió un nuevo Fénix, del que sólo tenemos noticia del título; y el cómico Eubulo por las mismas fechas compu-

54 Para los detalles sobre las citas de las fuentes, cf. la ed. de Frazer de la Biblioteca de APOLODORO, col. Loeb, Londres, 1921, vol. II, pág. 74s., n. 2.

55 Cf., por ejemplo, los Frs. 804 y 807. 
so una pieza cómica homónima, sobre la que Hunter ${ }^{56}$ propone que el argumento era mitológico, frente a la sugerencia de Edmonds de que aquí habría que tender El fenicio. Pero aún hay más: el latino Enio escribió otro Fénix, del que la crítica filológica suele poner como modelo la versión euripídea, pero que en cualquier caso versaba igualmente sobre este episodio amoroso, como, entre otros, nos deja ver el Fr.315 Warmington.

De otro lado, tenemos algunos testimonios de que esta temática trágica, al menos en la variante euripídea, gozó de una cierta popularidad: en Aristófanes ${ }^{57}$ se parodiaba el estado lastimoso de Fénix una vez cegado por su padre, y la misma burla irónica está dirigida a Eurípides unos versos más arriba. Por otro lado, en La samia de Menandro ${ }^{58}$, en la escena del enfrentamiento entre Mosquión y su padre Démeas en torno a la hetera, parece que está haciéndose eco del más tenso debate que debió de haber entre Amíntor y Fénix, y lo normal es que tuviese in mente la versión euripídea o, al menos, una cualquiera de las otras posibles versiones trágicas, pero, en cualquier caso, lo que es bastante probable es que le era familiar una escena semejante en la Tragedia anterior.

Tipologicamente el caso del Fénix euripídeo presentaba un esquema modélico, puesto que se dan en él los cinco elementos básicos al principio mencionados. Además, en esta ocasión tenemos constancia en los fragmentos conservados de la existencia de una escena de enfrentamiento directo entre padre e hijo; y en el descubrimiento de la verdad al final, después del catigo de la ceguera, tal vez tomaba parte Peleo, como a veces se ha sugerido basándose en la información complementaria aportada en este caso por el latino Enio.

4.5. La situación en el quinto triángulo (Atamante / Creteo / Demódica / Frixo) es más confusa, y ello tanto en lo concerniente al propio relato mítico como en su incidencia en la Tragedia.

La figura de Atamante está esencialmente relacionada con la compleja peripecia derivada de sus tres matrimonios, en los que las sucesivas esposas, adoptando el tradicional papel de «madrastra» para con los hijos habidos en los matrimonios anteriores, intentan apartarlos en beneficio de los suyos propios. Y en esta complicada madeja tienen una relevancia especial Frixo y Hele, los dos hijos de Atamante nacidos del primer matrimonio de Néfele: ambos van a verse

56 R. L. HunTER, Eubulus. The fragments, ed. with a commentary, Cambridge, 1983, pág. 213

57 ARISTÓfANES, Los acarnienses, 421-423.

$58 \mathrm{Vv}$. 128ss. 
expuestos a una inmolación inmerecida, aunque al final serán liberados por la intervención de su madre, que les proporciona un carnero de toisón de oro en el que serán transportados por los aires hasta la Cólquida.

Las causas de esa pretendida culpabilidad de Frixo, que está a punto de acarrearle la muerte en una pira, son diversas según las tradiciones mitográficas, aunque la interpretación general más extendida es la de que Ino, segunda esposa de Atamante, pretende acabar con la vida de Frixo y de su hermana en un intento de que sus propios hijos pasen así a ocupar un lugar preferente ante Atamante. Pues bien, en un momento dado se crea una variante muy distinta: Demódica, mujer de Creteo, que es a su vez hermano de Atamante, se enamora de su sobrino Frixo y trata de seducirlo en vano, tras lo cual lo calumnia ante Creto y Atamante exigiendo el correspondiente castigo, punto éste de la variante en donde se retorna a la línea central en la que veíamos a Frixo a punto de ser inmolado en un altar.

Esta variante del relato mítico de Frixo se atiene en lo fundamental al esquema del «motivo de Putifar». No obstante, presenta algunos problemas graves en el propio campo de la narración mitográfica. En primer lugar, la fuente que entra en una mayor pormenorización (Higino, Tratado de Astronomía, II 20.2) nos indica que la mujer era en esta ocasión tía del joven pretendido, lo que vanaliza y complica el esquema originario ya comentado. Ahora bien, el aspecto más conflictivo es el concerniente a su época de aparición. Las dos únicas fuentes a nuestra disposición son la mencionada de Higino y el escolio a Píndaro, Pítica IV $288 \mathrm{a}^{59}$, con la variante de que este último considera a Demódica madrastra de Frixo y no tía. Se trata, pues, de dos testimonios tardíos, lo que hablaría en favor de una época reciente para esta variante del mito de Frixo. Pero la situación se complica con la afirmación del escoliasta aludido, que nos dice que Píndaro en los Himnos ${ }^{60}$ llamaba Demódica a la madrastra de nuestro joven héroe. Pues bien, a partir de esta coincidencia en el nombre del personaje femenino Pearson ${ }^{61}$ sugiere que esta otra tradición arranca ya al menos de Píndaro y que, por lo tanto, era conocida en el mo-

59 El pasaje pindárico (v. 162 de la nueva numeración) nos dice que Frixo con la ayuda del carnero enviado en su auxilio «se libró del mar y de los impros dardos de su madrastra». Y en explicación de esta sucinta referencia del poeta beocio el escoliasta menciona el episodio del enamoramiento de la madrastra, de la que a continuación dice que en los Himnos recibe el nombre de Demódica. De otro lado, el comentarista muy probablemente se equivoca al menos cuando afirma que en el Atamante de Sófocles se la llamaba Néfele.

60 Pindaro, Fr. 49 Măhler. 255-7.

61 A. C. Pearson, «Phrixus and Demodice. A note on Pindar, Pyth IV, 162f.m, CR 23, 1910 , 
mento de apogeo de nuestros tres grandes trágicos en el propio siglo $\mathrm{V}^{62}$. Pero, y a pesar del ingenio del comentario de Pearson, una tal antigüedad no parece muy fundada ante la ausencia total, entre otras razones, de cualquier otra referencia hasta las dos fuentes arriba mencionadas, indiscutiblemente tardías. De otro lado, iría en contra de una tal suposición el que Eurípides, un poeta tan aficionado al «motivo de Putifar» como estamos viendo en esta páginas y que escribió dos tragedias tituladas ambas Frixo, no utilizase en ninguna de las dos ocasiones este motivo como base argumental, aunque sobre esto volveré más abajo.

En este estado de cosas, ¿cuál es la situación de la Tragedia al respecto? El área mítica de Atamante, con sus diversas mujeres y los hijos que fue teniendo con ellas, ha sido un tema muy productivo en la Tragedia. Tanto los trágicos mayores como los menores escribieron varios Atamantes e Inos, pero en nuestro caso lo que más nos importa son los diversos Frixos que subieron a escena, puesto que es en éstos en los que, a juzgar por el título, podría darse la variante mitográfica aludida. Pero en esta ocasión la información de que disponemos es insufíciente. Sabemos que Eurípides compuso dos piezas con este título y, aunque la crítica disiente en distintos aspectos, todos coinciden en que en ningún caso se trataba del episodio de Frixo y Demódica $^{63}$.

También Sófocles escribió un Frixo, pero tampoco aquí disponemos de datos seguros. Ya Welcker, en su famosa y monumental obra de $1839^{64}$, sugirió el motivo de Putifar como nudo argumental de la adaptación sofoclea, basándose en que aquí Frixo sería el personaje central de la acción dramática mientras que en el Atamante sofocleo el protagonismo estaría a cargo del padre, aunque también en torno a una situación de angustia del hijo, la creada por la envidia de Ino, o sea, el «motivo de la madrastra». Como se ve rápida-

62 El filologo inglés intenta fundamentar su propuesta recurriendo, además, a demostrar la antiguledad del motivo del enamoramiento a través de los ojos y el empleo de la metáfora del «dardo» (cf. nota 59) en referencia al golpe de mirada. También C. ROBERT (cf. nota 38), p. 48, parece inclinarse en la misma dirección, aunque el erudito alemán no entra en grandes pormenores y sólo alude al hecho de la coincidencia en el nombre para atribuir al episodio la procedencia pindárica.

${ }^{63}$ La publicación de un resto papiráceo conteniendo diversos argumentos euripídeos $(P$. Oxy 2455 , frs. 14, 16 y 17) nos ha confirmado tanto la existencia de este doblete como el hecho de que ninguna de las dos piezas desarrollaba el tema del arrebatado amor de Demódica por Frixo. Para un estado de la cuestión, cf. H. VAN LOOY, Zes verloren tragedies van Eurípides. Bruselas, 1964, págs. 132-84 (res. en francés, págs. 315-20), y R. AELION, Euripide héritier d'Eschyle, Paris, 1983, t. I, págs. 277-81.

64 Die griechische Tragödien mit Rücksicht..., págs. 317-9. 
mente, el punto de apoyo no es muy estable, aunque no imposible. Personalmente, y por razones de índole externa, me cuesta creer que Eurípides no utilizase este nuevo caso del motivo de Putifar, si es que ya se había configurado dicha variante mitográfica en su época, dado su indiscutible gusto por una temática tal y a la vista de que compuso dos obras con este mismo título, lo que supone en todo caso que este área mítica le era muy próxima ${ }^{65}$. De otro lado, el tradicional ${ }^{66}$ paralelismo de contenido en correspondencia a la identidad de títulos hablaría igualmente en contra de aplicar al Frixo sofocleo el motivo de
Putifar.

Tenemos noticia igualmente de un Frixo de Aqueo $^{67}$ y de otro tal vez de Timocles ${ }^{68}$ en el siglo IV, pero carecemos en ambos casos de la mínima infor-
mación concluyente.

En la Tragedia latina sabemos que Enio y Acio escribieron un Atamante cada uno. De la versión de Enio la crítica ya desde Ribbeck ${ }^{69}$ ha estado de acuerdo en relacionarla con la Fábula 4 de Higino, que a su vez se basaba en la Ino de Eurípides. Pero no hay la misma unanimidad en lo concerniente a la pieza de Acio: Ribbeck ${ }^{70}$ y, más recientemente, Warmington ${ }^{71}$ sugieren el mencionado pasaje de la Astronomía de Higino, lo que supondría el primer testimonio, tanto escénico como mitográfico, de los amores de Demódica por Frixo. Sin embargo, el contenido de los siete fragmentos conservados de la adaptación aciana es muy general, de forma que todos son aplicables a otros varios contextos temáticos: en este sentido, y con apoyos de corte lingüístico, D'Anto ${ }^{72}$ ha rechazado categóricamente la vieja propuesta de Ribbeck y sugerido a su vez las Fábulas 1 y 2 de Higino, lo que está más en consonancia con el tratamiento de la Tragedia griega.

${ }^{65}$ Este razonamiento debería de ser efectivo incluso entre quienes suponen que Eurípides recreó el mismo argumento en la segunda tragedia, con la introducción solamente de algunos elemen-
tos distintos (cf., p. e., H: VAN LOOY, op. cit. en nota 63) nombre propio.

6 Aunque, por supuesto, hay

67 AQUEO, TrGF 2 F39 Snell-Kannicht.

68 TIMOCLES, THGF 86 T 3 ?

69 O. RıввеCK, Die römische Tragödie im Zeitalter der Republik, Hildesheim, 1968, pág.
204s. (ed. orig., Leipzig, 1875).

${ }^{70}$ O. RIBBECK, op. cit. en la nota anterior, págs. 526-8.

71 E. H. WARMINGTON, Remains of old Latin, Londres, Loeb, vol. II, págs. 376-80.

72 V. D'ANTo, «L'Athamas di Ennio e di Accio», BStudLat, temente en su libro $L$. Accio. I frammenti bliografía más completa, cf. A. PocıÑ A El tragedie, Lecce, 1980, págs. 271-6. Para una bina 154s. 
En conclusión, frente a la activa producción dramática constatada en los precedentes casos del motivo de Putifar, vemos que en el caso de Atamante/Creteo-Demódica-Frixo no tenemos realmente apoyo estable alguno para afirmar que subiese en alguna ocasión a escena. Incluso es necesario dudar de la antigüedad de la aparición de la propia variante mitográfica. Aunque nada hay en contra de su existencia temprana, los datos de que disponemos nos empujan a retrasar su aparición.

4.6. He dejado para el final el triángulo más conocido: Teseo / Fedra / Hipólito. No voy a extenderme aquí en una descripción pormenorizada del material existente, labor que ya he acometido en un número anterior de esta misma Revista $^{73}$. Ahora sólo querría detenerme a hacer hincapié en cómo el esquema básico del motivo genérico de Putifar se ve alterado por la peculiaridad que aporta la figura de Hipólito, un personaje que rechaza no sólo las propuestas de un amor deshonesto sino las de cualquier otro tipo, puesto que él pertenece al área anímica de Ártemis, la diosa normalmente representante de la eterna virginidad. Y esta circunstancia será la que conduzca a Hipólito a un desenlace distinto al que experimentan los demás jóvenes héroes vistos más arriba: todos ellos, al final de la peripecia y una vez en evidencia su honestidad, salen triunfantes y retornan a una existencia feliz, en la que el matrimonio, o sea, una relación amorosa ordenada, es el destino tradicional que les espera. Frente a ellos Hipólito se derrumba en la autodestrucción, aunque también él al final haya quedado libre de culpa en su relación con Fedra; pero también él es culpable al haber elegido ese camino unidireccional de reverencia a Ártemis, con el consiguiente desprecio del ámbito de Afrodita, la diosa patrocinadora de la relación amorosa. A mi juicio éste es el elemento que hace que Hipólito muera, frente al final feliz que alcanzan los restantes jóvenes héroes del motivo de Putifar en el mito griego.

5. Después del análisis minucioso llevado a cabo más arriba en el material existente, querría ahora simplemente destacar, con brevedad y a título de conclusión, los hechos más llamativos. En primer lugar, es fácilmente observable el atractivo que tuvo este tipo de motivo del folktale no sólo en el mito griego sino también, y con mayor incidencia, en la Tragedia, puesto que hemos ido viendo cómo los diversos poetas gustaron de escenificar una y otra vez este tipo de temática, y de una manera especial Eurípides. Más aún: en alguna ocasión la

73 J. M." LuCAS, «Mito y Tragedia: Hipólito y Fedra, dos vidas rebeldes», EPOS 5, 1989, 35-56. 
Tragedia llegó incluso a alterar la versión homérica, con la pretensión de adecuarla al esquema prototipo de lo que venimos llamando «motivo de Putifar». Finalmente, el caso de Hipólito nos ofrece la posibilidad de contemplar la inclusión de un componente nuevo dentro de la vieja estructura del relato tradicional ${ }^{74}$.

74 Cuando prácticamente había concluido la elaboración de este trabajo como Comunicación destinada al VIIl Congreso Nacional de la Sociedad Española de Estudios Clásicos (cf. nota inicial), el Prof. François Jouan, haciendo gala una vez más de su infinita amabilidad, me proporcionó una separata de su trabajo «Femmes ardentes et chastes héros chez Euripide», aparecido un año antes y que yo desconocía. Aunque ambos trabajos persiguen fines distintos, quiero aquí dejar constancia de mi agradecimiento as como de la utilidad que me proporcionaron tanto esas páginas como las indicaciones personales que el Prof. Jouan me hizo en aquella reunión estival de Mérida. 